\title{
ESTUDO DE BRIQUETAGEM DE EUCALYPTUS SP. PARA COMBUSTÃO
}

Emmanuel Belga Rodrigues -belgarodrigues@gmail.com

Maria Eduarda Belga Rodrigues-dudabelga@gmail.com

Murilo Ramos Chiconeli-murilo.ramoskta@hotmail.com

Rafael Coelho-rcoelho6969@gamil.com

Tiago Bittencourt Nazaré - tiago@unis.edu.br

RESUMO: O presente artigo apresenta um estudo sobre o processo de briquetagem de resíduos de Eucalyptus sp. compactados através de uma prensa para combustão. Foram realizados diferentes testes para três tratamentos de resíduos de eucalipto para a briquetagem através de uma prensa de 15 toneladas, sendo possível identificar resultados satisfatórios. Conclui-se que o aproveitamento de resíduos de eucalipto para briquetagem com a finalidade de combustão alcançou resultados adequados em dois testes realizados a partir de um dos tratamentos.

Palavras-chave: briquete, eucalipto, combustão

\section{INTRODUÇÃO}

Em 2016 a biomassa foi responsável por uma geração de 54 TWh, voltando a ser a segunda fonte de energia a ser a mais utilizada no Brasil segundo o Boletim Mensal de Energia de dezembro de 2016, registrando 8,8 \%, ultrapassando o gás natural responsável por 8,1 \% na Oferta Interna de Energia Elétrica (OIEE), onde $67 \%$ foram de bagaço e palha da cana, totalizando $36 \mathrm{TWh}$. Visto isso, a bioeletricidade vem impulsionando o uso de fontes renováveis no País, como consequência disso, o processo de briquetagem pode vim a ser uma boa alternativa.

A briquetagem consiste na aglomeração de partículas finas por meio de pressão, com auxílio ou não de um aglomerante, permitindo a obtenção de um produto não só compactado, porém com forma, tamanho e parâmetros mecânicos adequados. Redução de volumes do material, em alguns casos, além dos benefícios tecnológicos, permite que materiais finos possam ser transportados e armazenados de forma mais econômica. (Carvalho e Brinck 2010)

A recente preocupação ambiental, resultando em leis cada vez mais rígidas, além da necessidade de aproveitar economicamente os resíduos e as partículas finas geradas no beneficiamento de minérios fez com que a briquetagem voltasse a ser um importante alternativa para aglomerar valor econômico (CARVALHO e BRINCK, 2010).

Conforme GENTIL (2008), a entrada do briquete no mercado indiretamente reduz o desmatamento de florestas nativas, e associado ao fato de que, segundo a ABRAF (2006) $85 \%$ das florestas plantados respondem por todos os produtos de origem florestal reduzem a pressão antrópica, gerando resíduos que podem ser utilizados na produção de briquetes. $\mathrm{O}$ aproveitamento dos resíduos gerados pelo desgaste inadequado da madeira em serrarias, indústrias madeireiras e construções civis vem se tornando uma ambição no mercado financeiro pelos empresários, sócio, produtores, etc. Em empresas de grande porte, onde a produção madeireira é elevada, os resíduos de diferentes tipos de madeiras são descartados sem o reaproveitamento com tendência de aumento de estocagem. $\mathrm{O}$ fato da reciclagem, além de reduzir o acúmulo de resíduos nas indústrias pode se tornar um grande retorno financeiro.

O objetivo deste artigo é investigar a tecnologia e a economia do briquete de madeira no Brasil, através de testes de briquetes com serragem de Eucalyptus sp e verificar sua viabilidade para combustão; observar as características tecnológicas da matéria-prima, do briquete de madeira e do processo industrial da briquetagem; analisar 
o comportamento do mercado e da economia do briquete de madeira, assim como investigar o custeio gerencial do processo industrial de briquetagem e estudar temas associados ao briquete como sejam analisar aspectos energéticos conjunturais, metodologias de investigação científica, aspectos culturais, ambientais, legais e operacionais do briquete de madeira no Brasil.

\section{REFERENCIAL TEÓRICO}

\subsection{Briquete}

Conforme Paula et al. (2009) o processo de briquetagem consiste na compactação de biomassa em uma pequena unidade de área, concentrando grande quantidade de energia, proporcionando no mínimo cinco vezes mais energia do que o material descompactado. Também, "a briquetagem se caracteriza pela aglomeração de partículas de granulometria fina, resultante da ação de uma força de pressão sobre o material" (Ribeiro et al. 2010), tornando a densidade energética do briquete três vezes maior que a da lenha, e corroborando com Paula et al. (2009), em relação ao material descompactado, a energia chega a ser cinco vezes maior, "ou seja, em $1 \mathrm{~m}^{3}$ de briquete espera-se 5 vezes mais energia que em $1 \mathrm{~m}^{3}$ de resíduo".

Segundo Furtado et al. (2010), a fabricação de briquetes de resíduos de madeira aplicadas em pressões de diferentes toneladas para compactação, tem mais poder energético do que a própria matéria-prima. Ainda Quirino (2000) afirma que os resíduos vegetais podem ser compactados pela briquetagem, assim feito um processo de controlar teor de umidade e compactar os resíduos em baixas medidas granulométricas, tendo como vantagem um poder energético alto e a preservação de meio ambiental.

Tornando a briquetagem um processo mais vantajoso, uma vez que além de concentrar grande quantidade de energia em uma pequena área, facilita a armazenagem reduzindo o custo com o transporte uma vez que conforme Ribeiro et al. (2010), em decorrência do fato do material estar condensado, poderá ser transportado uma quantidade muito superior de biomassa em espaço físico reduzido.

\subsection{Eucalipto}

Segundo Instituto Brasileiro de Geografia e Estatística (IBGE, 2015) foram plantados 7.444.731 hectares de eucalipto no Brasil para fins industriais, onde Minas Gerais lidera como a maior área de floresta de eucalipto plantada seguido por São Paulo e Mato Grosso do Sul, de acordo com figura 1.

Figura 1 - Distribuição por estado

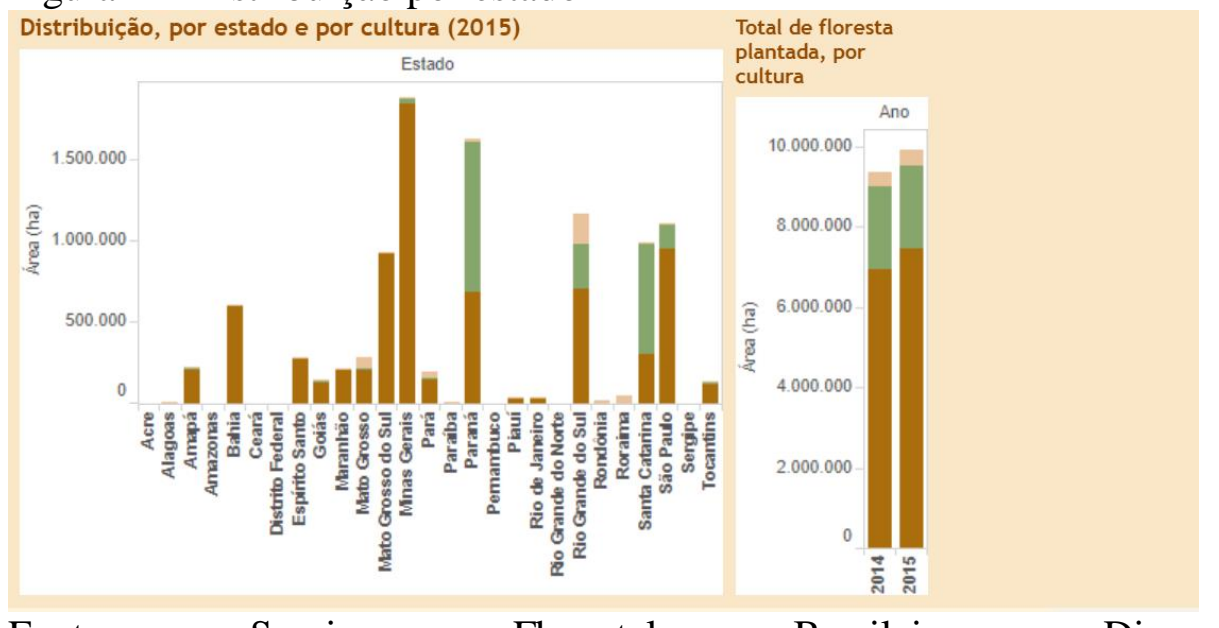

Fonte: Serviço Florestal Brasileiro. Disponível em:

<http://www.florestal.gov.br/snif/recursos-florestais/as-florestas-plantadas> 
A partir da figura 1, ainda pode-se observar que houve um aumento na plantação de eucalipto quando comparado com a plantação em 2014, mostrado pelo gráfico representado pela cor marrom, em comparação com a plantação de pinus representado pela cor verde e outras espécies representado pela cor bege. Nota-se a prioridade da plantação de eucalipto nos estados brasileiros, exceto pelo estado de Paraná e Santa Catarina, onde se prioriza a plantação de pinus.

Conforme Ribeiro et al. (2010) um dos problemas das industrias madeireiras, é a quantidade de resíduos que são gerados, girando em torno de $19.255 .000 \mathrm{~m}^{3} / \mathrm{ano}$ de resíduos, que pode ser aproveitado como fonte de energia através da produção de briquetes. Reforçando Silva et al. onde diz que "estes resíduos, podem ser aproveitados na produção de energia convertendo-os em briquetes (briquetagem), agregando valor à cadeia produtiva num processo mais limpo (Produção + Limpa ou $\mathrm{P}+\mathrm{L}$ )”.

\section{METODOLOGIA}

O trabalho foi realizado no Laboratório de Fundamentos de Materiais da Faculdade Integrada de Cataguases -FIC UNIS a partir do dia 31/07/2017. Os materiais utilizados na produção dos briquetes foram resíduos de serragem de Eucalyptus sp. Adquirido em uma serraria de pequeno porte localizada em Vista Alegre- MG distrito de CataguasesMG.

Inicialmente foi investigado o teor de umidade da amostra de resíduos de serragem de Eucalyptus sp. Para este fim, foi separado 100 gramas da amostra de Eucalyptus sp para passar por um processo de secagem a ar quente numa duração de cinco minutos e logo em seguida pesado novamente, obtendo-se $13 \%$ de teor de umidade identificado a partir da formula em conformidade com Walbert (2011).

$\frac{\text { material úmido-material seco }}{\text { material umido }} * 100$

\subsection{Tratamento do material}

O material obtido de Eucalyptus sp. foram trituradas até atingirem medidas granulométricas mínima possível e em seguida a partir do resíduo de serragem obtida do processo de trituração foram adotados três tipos de tratamentos. Para o tratamento um (T1) foi utilizado o resíduo de serragem obtida do processo de trituração com teor de umidade de $13 \%$. Para o tratamento dois (T2) o resíduo serragem foi pré-aquecida a ar seco durante 10 minutos para atingir teores de umidade menores que $13 \%$. No tratamento três (T3) o resíduo de serragem passou por uma peneira de 100 mesh $(0,149$ $\mathrm{mm}$ de abertura), obtendo granulometria iguais e menores a $0,149 \mathrm{~mm}$.Para os três tratamentos não foram utilizados nenhum tipo de aglomerante.

Os briquetes obtidos das amostras de resíduo de serragem dos três tratamentos foram expostos a temperatura ambiente que variaram de $22^{\circ}$ e $33^{\circ}$ durante três dias sem nenhum método de armazenagem.

\subsection{Produção do briquete}

Foram realizados diferentes testes para as amostras de resíduo de serragem obtidas pelos três tratamentos e produzidos dois briquetes para cada teste realizado, utilizando dezessete gramas para cada briquete. A prensa hidráulica da marca Ribeiro de 15 tonelada foi utilizada para a produção dos briquetes.

Para as amostras de resíduo de serragem obtidas pelo tratamento um foram realizados cinco testes entre os dias 02/09/2017 e 27/09/2017. Em todos os testes foram aplicados pressão de quinze toneladas e, variando apenas o tempo de prensagem. No teste um o tempo de prensagem foi de cinco minutos, no teste dois foi de dez minutos, no teste três foi de quinze minutos, no teste quatro foi de dezoito minutos e no teste cinco o tempo foi de vinte minutos. 
$\mathrm{Na}$ produção dos briquetes a partir das amostras obtidas do tratamento dois, foram realizados dois testes. No teste um foi aplicado pressão de dez toneladas e um tempo de prensagem de cinco minutos, já no segundo teste foi aplicado uma pressão de quinze toneladas em um tempo de cinco minutos de prensagem.

Para as amostras de resíduos de eucalipto obtidas do tratamento três foram realizados três testes, no teste um foi aplicado quinze toneladas na compactação e um tempo de cinco minutos de prensagem, no teste dois foi aplicado dez toneladas e o tempo de prensagem de cinco minutos, e no teste três foi aplicado quinze toneladas durante trinta segundos de prensagem.

Tabela 1 - Tempo de prensagem e peso aplicado.

\begin{tabular}{|l|l|l|l|l|l|l|l|}
\hline & \multicolumn{2}{|l|}{ Tratamento 1 } & \multicolumn{2}{l|}{ Tratamento 2 } & \multicolumn{2}{l|}{ Tratamento 3 } \\
\hline & $\begin{array}{l}\text { Peso } \\
\text { aplicado }\end{array}$ & $\begin{array}{l}\text { Tempo de } \\
\text { prensa }\end{array}$ & $\begin{array}{l}\text { Peso } \\
\text { aplicado }\end{array}$ & $\begin{array}{l}\text { Tempo de } \\
\text { prensa }\end{array}$ & $\begin{array}{l}\text { Peso } \\
\text { aplicado }\end{array}$ & $\begin{array}{l}\text { Tempo de } \\
\text { prensa }\end{array}$ \\
\hline Teste 1 & $15 \mathrm{~T}$ & $5 \mathrm{~min}$ & $10 \mathrm{~T}$ & $5 \mathrm{~min}$ & $15 \mathrm{~T}$ & $5 \mathrm{~min}$ \\
\hline Teste 2 & $15 \mathrm{~T}$ & $10 \mathrm{~min}$ & $15 \mathrm{~T}$ & $5 \mathrm{~min}$ & $10 \mathrm{~T}$ & $5 \mathrm{~min}$ \\
\hline Teste 3 & $15 \mathrm{~T}$ & $15 \mathrm{~min}$ & - & - & $15 \mathrm{~T}$ & $30 \mathrm{~s}$ \\
\hline Teste 4 & $15 \mathrm{~T}$ & $18 \mathrm{~min}$ & - & - & - & - \\
\hline Teste 5 & $15 \mathrm{~T}$ & $20 \mathrm{~min}$ & - & - & - & - \\
\hline
\end{tabular}

\subsection{Queima do briquete}

A queima do briquete foi realizada dia 05/10/2017 a partir de um maçarico da marca Western e depois foi coletado os dados do tempo de queima. Os briquetes obtidos a partir dos testes foram submetidos em condições iguais, queimados em temperatura ambiente.

\section{RESULTADOS}

A figura 2 mostra os briquetes obtidos pelos cincos testes realizados a partir das amostras de resíduos de serragem do tratamento um. Respectivamente são os briquetes obtidos pelo teste um, dois, três, quatro e cinco:

Figura 2 - briquetes a partir da amostra.

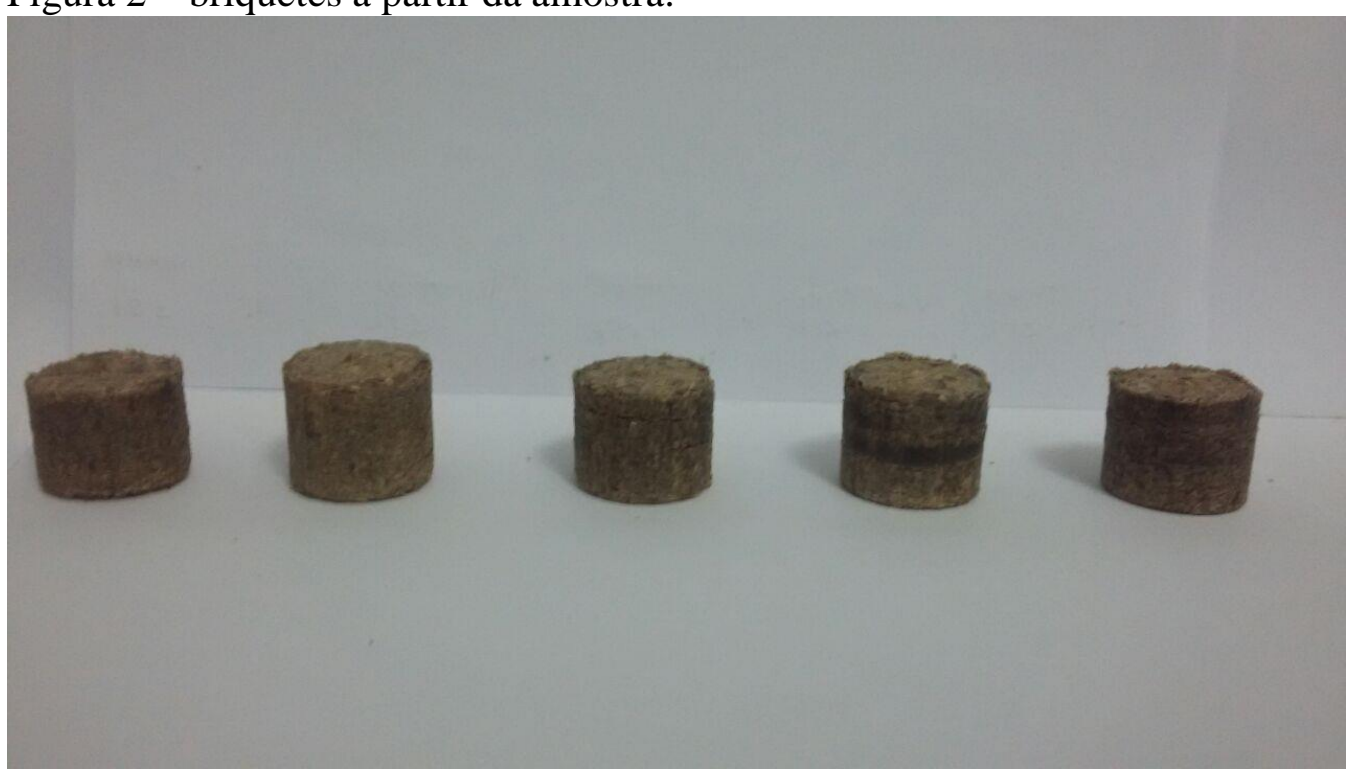

Fonte: Próprio autor. 
Os briquetes obtidos pelos cinco testes mostrados pela figura acima, não apresentaram expansões longitudinal significativas, porém conforme os estudos realizados por Yamaji et al. (2013), briquetes expostos a ambientes de elevadas umidades apresentam grande expansão longitudinal devido a absorção da umidade pelo briquete, logo é comum o briquete apresentar expansões longitudinal. Os briquetes do teste três, quatro e cinco apresentaram uma coloração mais escura nas laterais, devido a liberação da lignina que é o aglomerante natural do tipo polímero termoplástico presente na biomassa que segundo Rowell (1987) o calor no processo de compactação ajuda na liberação da lignina. Pelos testes três, quatro e cinco ficarem mais tempo sob pressão, logo mais tempo em temperaturas elevadas a lignina aglomerou com mais facilidade as partículas da serragem, apresentando maior resistência que os briquetes obtidos pelos testes um e dois.

Foi verificado que os briquetes dos cinco testes obtiveram tempo de queima próximos, não apresentando diferenças significativas. Para o briquete obtido do teste um o tempo de queima foi de 10 minutos e 59 segundos (10:59). O briquete do teste dois teve o tempo de queima de 13 minutos e 57 segundos (13:57). O briquete do teste três durou 13 minutos e 1 segundo (13:01). O tempo de queima do briquete obtido pelo teste quatro foi de 11 minutos e 96 segundos (11:56). Por fim, o briquete do teste cinco teve o tempo de queima de 10 minutos e 6 segundos (10:06). Os briquetes do teste quatro e cinco apresentaram maior resistência que os briquetes do teste um, dois e três, mostrando que quanto mais aglomerado as partículas estiverem maior a resistência a queima. Conforme observado pela tabela um abaixo:

Tabela 2 - Tempo de combustão.

\begin{tabular}{|l|l|l|l|l|l|}
\hline Teste 1 & Teste 2 & & Teste 3 & Teste 4 & Teste 5 \\
\hline $10: 59 \mathrm{mn}$ & $\begin{array}{l}13: 57 \\
\mathrm{mn}\end{array}$ & & $13: 01 \mathrm{mn}$ & $11: 56 \mathrm{mn}$ & $10: 06 \mathrm{mn}$ \\
\hline
\end{tabular}

Fonte: Próprio autor.

A figura 3 mostra os briquetes produzidos do teste um e dois respectivamente, obtidos a partir das amostras do tratamento dois:

Figura 3: briquetes a partir da amostra dois.

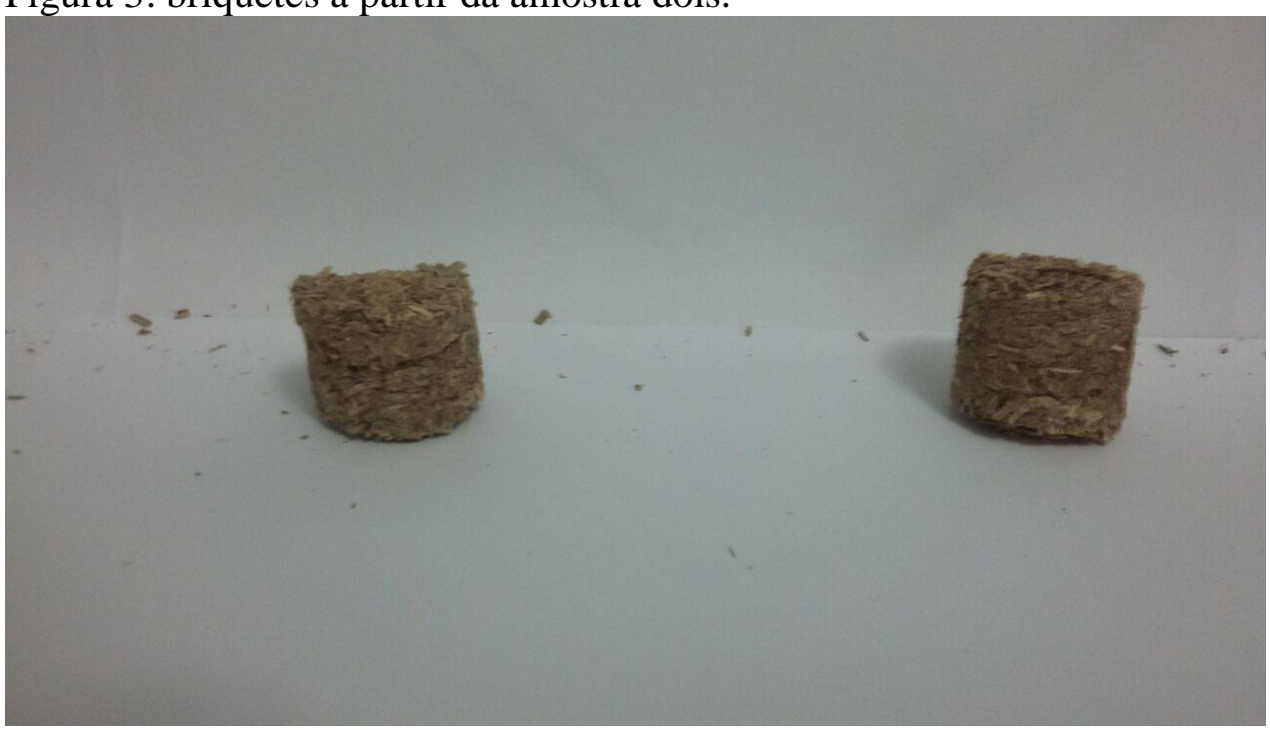

Fonte: Próprio autor. 
Os briquetes obtidos dos dois testes, conforme mostrado na figura acima, apresentaram uma expansão longitudinal significativa, afetando em sua resistência tornando-os quebradiços, porém o briquete do teste dois foi o que apresentou menos instabilidade, mostrando que uma maior força de pressão colabora para a resistência do briquete.

Não foi realizado teste queima para os briquetes obtidos da amostra dois, por não apresentarem viabilidade para um briquete, uma vez que os testes realizados obtiveram briquetes quebradiços e de pouca resistência.

A figura 4 mostra os briquetes obtidos pelo teste um, dois e três respectivamente, do resíduo de serragem da amostra três:

Figura 4: briquetes a partir da amostra três.

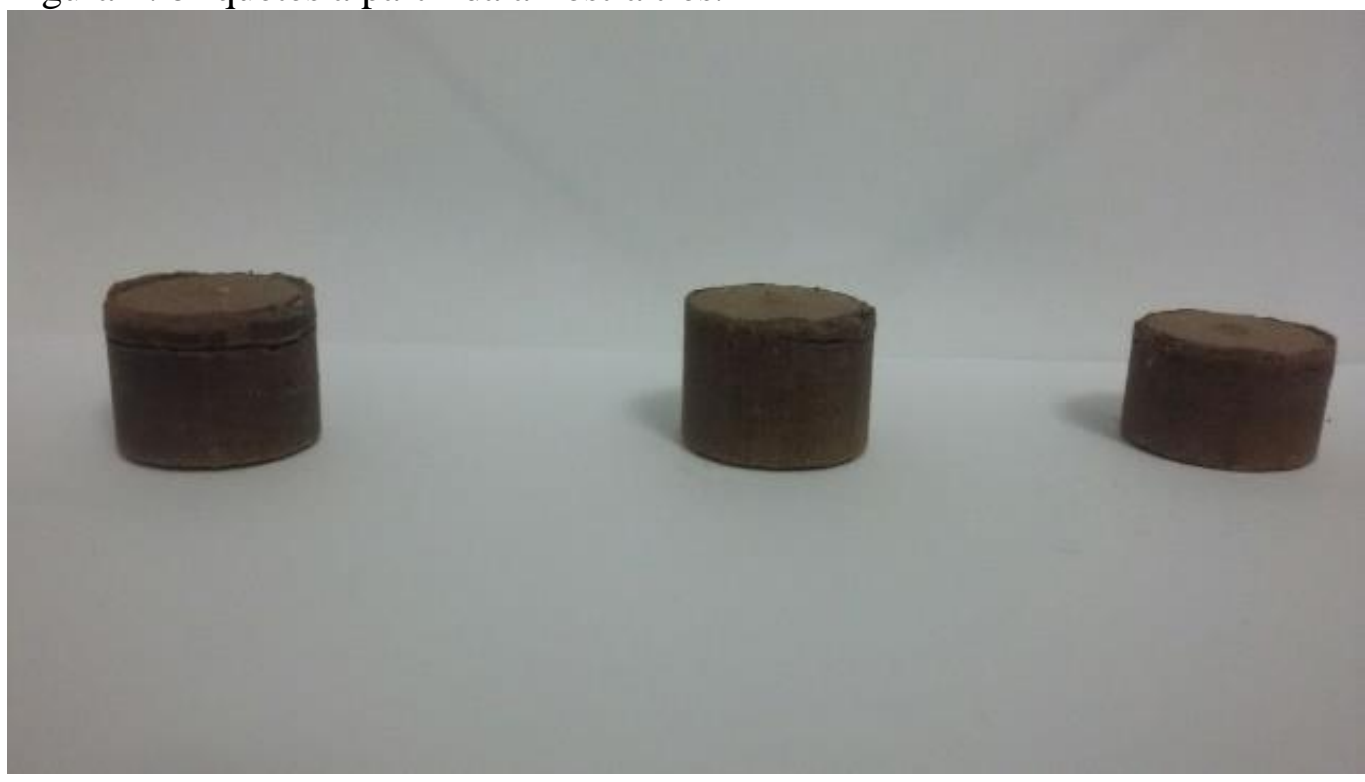

Fonte: Próprio autor.

Os briquetes óbitos pelos três testes mostrados na figura acima, apresentaram alta resistência e uma expansão longitudinal mínima devido à granulometria da serragem, uma vez que a granulometria é uma influência direta na resistência do briquete, pois, as partículas menores ajudam a preencher os espaços vazios. (FERRAGUTI et al., 2012; GONÇALVES et al., 2013; NAKASHIMA, 2013).

Além da alta resistência apresentada, os briquetes dos três testes apresentaram coloração escura nas laterais, já visto em testes do tratamento um, porém as partículas apresentaram uma melhor aglomeração mostrando que a granulometria também influencia na liberação de lignina.

A queima dos briquetes obtidos dos três testes apresentaram alta resistência a queima e não mantiveram queimando por tempo adequado para combustão. Os briquetes dos três testes mantiveram o tempo de queima próximos, variando de 3 a 7 segundos. Observou-se que o centro do briquete dos três testes não entraram em combustão revelando que uma menor granulometria das partículas dos briquetes influenciam na queima. Conforme mostrado na tabela dois.

Tabela 3 - Tempo de combustão.

\begin{tabular}{|l|l|l|}
\hline Teste 1 & Teste 2 & Teste 3 \\
\hline $3 \mathrm{~s}$ & $\cdots 6 \mathrm{~s}$ & $7 \mathrm{~s}$ \\
\hline
\end{tabular}

Fonte: Próprio autor. 


\section{CONCLUSÃO}

Após o estudo realizado neste trabalho, foi notado que os briquetes do teste quatro e cinco obtidos da amostra do tratamento um, apresentaram ser os mais viáveis para uso na combustão, uma vez que mostraram ter resistência adequada para o briquete e manteve a queima pelos maiores tempos obtidos dos testes realizados das três amostras. Os briquetes menos viáveis foram obtidos pelos testes realizados do tratamento dois, por não apresentarem resistência adequada e alta expansão longitudinal, sendo descartado para testes de combustão. Os estudos dos testes da amostra três mostraram resultados adequados para resistência de um briquete, apresentando mínima expansão longitudinal, porém obtiveram resultados inferiores para uso na combustão por apresentarem muita resistência a queima e não mantiveram a combustão por muito tempo.

\section{REFERÊNCIAS BIBLIOGRÁFICAS}

ABRAF. Associação Brasileira de Produtores de Florestas Plantadas. Anuário Estatístico da ABRAF de 2006. São Paulo. Ed. ABRAF. $2006 . \quad$ Disponível em: 〈http://repositorio.unb.br/bitstream/10482/4499/1/2008_LuizVicenteBocornyGentil.pdf>. Acessado em: 08/05/2019.

COSTA, Danilo Ribeiro et al. Análise de briquetes de eucalyptus. Disponível em: $<$ http://www.remade.com.br/br/revistadamadeira materia.php?num=1460\&subject=Briquetes\&title=An \%E1lise\%20de\%20briquetes\%20de\%20eucalyptus >. Acesso em: 11/09/2017.

CHRISOSTOMO, Walbert. Estudo Da Compactação De Resíduos Lignocelulósicos Para Utilização Como Combustível Sólido. Universidade Federal de São Carlos. Sorocaba, 2011. Disponível em: $<$ https://repositorio.ufscar.br/bitstream/handle/ufscar/1164/CHRISOSTOMO_Walbert_2011.pdf?sequenc $\underline{\mathrm{e}=1>}$ Acesso em: 25/09/2017

FLORES, Wesley de Paula et al. Redução do volume de biomassa no processo de briquetagem. Disponível <http://www.remade.com.br/br/revistadamadeira_materia.php?num=1419\&amp;subject=E\%20mai > Acesso em: 18/09/2017.

Portal do Brasil. Em 2016, biomassa é a segunda maior fonte de energia. Revista do Governo do Brasil, 2017. Disponível em:<http://www.brasil.gov.br/infraestrutura/2017/03/em-2016-biomassa-e-asegunda-maior-fonte-de-energia $>$. Acesso em: 11/09/2017

QUIRINO, W. F. Briquetagem de Resíduos Ligno-celulósicos. Laboratório de Produtos Florestais LPF/IBAMA. $\quad$ Brasília, $2000 . \quad 10 \mathrm{p} . \quad$ Disponível em: <http://mundoflorestal.com.br/arquivos/briquetagem.pdf>. Acesso em: 25/09/2017.

SANTOS, Silmara Bispo et al. Compactação De Resíduos De Mdf E Eucalipto (Eucalyptus Sp.) Sob Diferentes Condições De Pressão E Temperatura. Disponível em: <http://www.iee.usp.br/agrener2015/sites/default/files/tematica8/920.pdf>. Acesso em: 11/09/2017

SILVA, D. A. et al. A Influência da Umidade em Propriedades Mecânicas de Briquetes Produzidos com Resíduos de Madeira (Eucalyptus sp. e Pinus sp.). Revista Virtual Química, 2017, 9 (3), no prelo, 4 de maio de 2017. Disponível em: 〈http://rvq.sbq.org.br/imagebank/pdf/DiegoSilvaNoPrelo.pdf >. Acesso em: $11 / 09 / 2017$

SILVA, Diego Aleixo et al. Caracterização De Biomassas Para A Briquetagem. Disponível em: 〈http://revistas.ufpr.br/floresta/article/view/39700/26929> Acesso em: 11/09/2017

Sistema Nacional de Informações Florestais. As Florestas Plantadas. Brasília, 16 de Outubro de 2017. Disponível em: 〈http://www.florestal.gov.br/snif/recursos-florestais/as-florestas-plantadas> Acesso em: 25/09/2017. 
Universidade Federal do Paraná- UFPR. Sinterização - Processos de Corte. Agosto de 2006. Disponível em: 〈http://www.madeira.ufpr.br/disciplinasivan/processoscorte_arquivos/Sinterizacao.pdf $>$ Acesso em: $09 / 10 / 2017$

Universidade Tecnológica Federal Do Paraná Campus Londrina Curso De Engenharia Ambiental. Produção E Caracterização De Briquetes Produzidos Com Resíduos Lignocelulosicos. OSHIRO, Thaís Liemi, Londrina: $2016 . \quad$ Disponível em: <http://repositorio.roca.utfpr.edu.br/jspui/bitstream/1/5480/1/LD_COEAM_2016_1_16.pdf >. Acesso em: $11 / 09 / 2017$

YAMAJI, Fábio Minoru et al. Análise Do Comportamento Higroscópico De Briquetes. Disponível em: <http://revistas.fca.unesp.br/index.php/energia/article/view/111/0>. Acesso em: 11/09/2017 